\title{
Desinformação e pós-verdade no contexto da pandemia da Covid-19: um estudo das práticas informacionais no Facebook
}

\author{
Disinformation and post-truth in the context of the Covid-19 \\ pandemic: a study of information practices on Facebook
}

\begin{abstract}
Andrea Heloiza Goulart ${ }^{\mathrm{a}, \text { * }}$
Ivette Kafure Muñoz ${ }^{a}$ (iD)

RESUMO: A enorme quantidade de informações sobre a pandemia da Covid-19 que circula na internet gera muitas dúvidas na população, contribuindo para alimentar um cenário em que desinformação e pósverdade se tornaram comuns. $\mathrm{O}$ artigo apresenta pesquisa sobre as práticas informacionais em redes sociais, no contexto da pandemia. Para tanto, três grupos públicos do Facebook têm sido observados desde o mês de abril de 2020, com o objetivo de se averiguar quais temas despertam mais interesse nos internautas, como os diferentes grupos encaram os acontecimentos e de que modo as práticas podem, eventualmente, se alterar ao longo do tempo. O estudo, em andamento, adota a netnografia por método e apresenta análises e resultados preliminares de duas datas específicas: 10 de abril, por marcar o início da coleta de dados, e 7 de julho, em que se registra o afrouxamento das medidas de isolamento social em grande parte do Brasil. Conclui-se que os grupos comportam-se de modos bastante distintos, de acordo com o propósito de cada um. Além disso, observa-se grande influência de fatores emocionais, que acabam por direcionar as práticas dos internautas, envolvendo-os em bolhas informacionais.
\end{abstract}

Palavras-chave: Desinformação; Pós-Verdade; Práticas Informacionais; Covid-19.

ABSTRACT: The huge amount of information circulating on the internet about the Covid-19 pandemic generates many doubts in the population, contributing to feed a scenario in which disinformation and post-truth have become common. The article presents research on information practices in social networks, in the context of the pandemic. To this end, three public Facebook groups have been observed since April 2020, with the aim of ascertaining which themes are of most interest to Internet users, how different groups face events and how practices may, potentially, change over time. The ongoing study adopts netnography as a method and presents preliminary analysis and results for two specific dates: April 10 , which marks the beginning of data collection, and July 7 , when the loosening of social isolation measures in a large part of Brazil is registered. It is concluded that the groups behave in very different ways, according to the purpose of each one. In addition, there is a great influence of emotional factors, which end up directing the practices of Internet users, involving them in information bubbles.

Keywords: Disinformation; Post-Truth; Information Practices; Covid-19.

\footnotetext{
a Programa de Pós-Graduação em Ciência da Informação, Universidade de Brasília, Brasília, DF, Brasil.

* Correspondência para:/Correspondence to: Andrea Heloiza Goulart. E-mail: andreagoulart@gmail.com. Endereço institucional: Universidade de Brasília, Faculdade de Ciência da Informação. Campus Universitário Darcy Ribeiro, Asa Norte, CEP: 70910-900 - Brasilia, DF - Brasil.
}

Recebido em/Received: 15/08/2020; Aprovado em/Approved: 01/12/2020.

Artigo publicado em acesso aberto sob licença $\mathrm{CC}$ BY 4.0 Internacional (C)( 


\section{INTRODUÇÃO}

O advento das tecnologias de informação e comunicação (TIC), em especial da internet, descentralizou os processos comunicativos, além de propiciar a livre circulação de informações, o que, a princípio, permite que os indivíduos se tornem mais autônomos e empoderados, principalmente em relação à hegemonia das indústrias de conteúdo (BEZERRA; SCHNEIDER; SALDANHA, 2013).

A explosão digital, contudo, tem facilitado em grande medida a proliferação da desinformação. Para Bezerra, Capurro e Schneider (2017), a disseminação de notícias falsas na web tornou-se um problema relevante para as grandes plataformas da internet. Os autores esclarecem que vivenciamos, atualmente, um contexto de hiperinformação e desinformação e relativizam o conceito de verdade com base na ideia de que "na luta política e econômica, há um importante papel na disseminação de 'verdades' ou 'meias verdades' ou 'três quartos de verdade' ou simplesmente 'mentiras', que podem ser insultos pessoais, difamações ou ameaças" (BEZERRA; CAPURRO; SCHNEIDER, 2017, p. 374).

Atrelado a isso, observa-se, ainda, o fenômeno conhecido como pós-verdade, em que fatos objetivos repercutem menos na opinião pública do que aqueles que apelam para a emoção e as crenças pessoais (SANTAELLA, 2018). De acordo com Araújo (2020), a pós-verdade está diretamente relacionada a um desinteresse pela verdade, ou seja, os indivíduos importam-se menos com a veracidade das informações do que com a carga emocional que elas carregam. Com isso, percebe-se um maior volume de atitudes norteadas por crenças e emoções do que com base no comportamento racional.

Nesse cenário, as redes sociais despontam como ambiente propício à disseminação de desinformação e ao universo da pós-verdade, uma vez que as informações que os indivíduos recebem por esse meio são menos diversas e plurais do que as encontradas em buscadores da web (SANTAELLA, 2018).

No contexto da pandemia da Covid-19, em que a própria ciência busca respostas para solucionar ou amenizar o problema de saúde pública mundial, desinformação e pósverdade figuram como ameaças ao combate à doença e à redução de sua incidência, uma vez que estimulam os sujeitos à resistência ativa, ou retórica, em relação às orientações fornecidas pela Organização Mundial da Saúde (OMS). Além disso, de acordo com a Agência Nacional de Telecomunicações (Anatel), houve aumento de 40\% a $50 \%$ do consumo de internet no Brasil, por conta do isolamento social durante a pandemia (LAVADO, 2020), o que reforça a importância da averiguação dos hábitos informacionais que os sujeitos cultivam na web.

Desenvolve-se, nesses termos, pesquisa sobre as práticas informacionais em redes sociais, em tempos de pandemia, com o objetivo de investigar de que modo os sujeitos lidam com as informações sobre a doença, que circulam nas redes sociais. Para isso, tem-se acompanhado três grupos públicos do Facebook, desde o mês de abril de 2020, a fim de se verificar como os internautas se relacionam com as informações sobre a Covid-19. Para fins do presente artigo, retratam-se dois momentos específicos, os dias 10 de abril e 7 de julho. O primeiro foi eleito por corresponder ao início da coleta de dados da pesquisa. O segundo foi selecionado porque, a despeito de os números da Covid-19 seguirem em trajetória ascendente, nesta data, muitos Estados e Municípios haviam retomado diversas atividades econômicas (VALENTE; SOUZA; TOKARNIA, 2020).

A perspectiva das práticas informacionais valoriza os elementos contextuais de busca, uso e compartilhamento de informação, reconhecendo nos indivíduos sua condição de integrantes de grupos e comunidades (SAVOLAINEN, 2007). Tais estudos consideram 
que o contexto influencia as ações dos sujeitos e vice-versa, e levam em conta situações de vida cotidiana e a obtenção de informações de maneira casual, sem que necessariamente se identifique uma lacuna de conhecimento (ROCHA; DUARTE; PAULA, 2017).

\section{DESINFORMAÇÃO E PÓS-VERDADE NO CENÁRIO BRASILEIRO}

Em 31 de dezembro de 2019, a Organização Mundial da Saúde (OMS) foi informada da ocorrência de casos de uma "pneumonia viral", em Wuhan, na República Popular da China. Em 9 de janeiro de 2020, autoridades chinesas relataram que o surto de infecções respiratórias agudas graves era causado por um novo tipo de coronavírus. Dois dias depois, em 11 de janeiro, os meios de comunicação chineses divulgaram a primeira morte causada pelo patógeno (WORLD HEALTH ORGANIZATION, 2020a).

A partir de 13 de janeiro, iniciou-se a confirmação de sucessivas ocorrências de infecção pelo novo coronavírus fora da China, sendo o primeiro caso na Tailândia, depois no Japão (16 de janeiro), seguidos por Estados Unidos (21 de janeiro), França (24 de janeiro) e Emirados Árabes (28 de janeiro) (WORLD HEALTH ORGANIZATION, 2020a). Em 30 de janeiro, com 98 casos confirmados em 18 países que não a China, a OMS declarou que caberia reconhecer o surto provocado pelo novo coronavírus como uma emergência de saúde pública de importância e alcance internacional (WORLD HEALTH ORGANIZATION, 2020b).

Em 11 de fevereiro, a nova doença passou a ser chamada de Covid-19, nome escolhido para se evitar que a enfermidade fosse relacionada um grupo de pessoas, a um país ou região, o que poderia resultar em estigmatização e preconceito. Constatada a rápida propagação da doença, em 11 de março, a OMS passou a considerar a Covid-19 uma pandemia (WORLD HEALTH ORGANIZATION, 2020a).

No Brasil, confirmou-se o primeiro caso da Covid-19 em 26 de fevereiro, na cidade de São Paulo (MINISTÉRIO DA SAÚDE, 2020). A partir de então, diversos Estados e Municípios passaram a adotar medidas para promover o distanciamento social, como o fechamento de escolas e estabelecimentos comerciais, na tentativa de contenção do avanço da pandemia (VALENTE, 2020).

Desde o início da crise, contudo, percebeu-se significativo desencontro de informações nos níveis Federal, Estadual e Municipal. Enquanto diversos Governadores e Prefeitos tomaram medidas para reduzir a circulação de pessoas, o Governo Federal agiu em sentido contrário, minimizando o problema de saúde e insistindo para que a sociedade se preocupasse em não desacelerar a economia (BRITO, 2020).

$\mathrm{Na}$ contramão do recomendado pela OMS e pelo Ministério da Saúde, o Chefe do Poder Executivo brasileiro posicionou-se contra o isolamento social, além de defender o uso da cloroquina para o tratamento da doença, remédio cuja eficácia não é chancelada pela comunidade científica. Tais atitudes fizeram com que as redes sociais Twitter, Facebook e Instagram apagassem postagens feitas pelo Presidente, por considerarem que as publicações geravam desinformação e apresentavam potencial danoso à população (MARQUES, 2020).

Nos meses subsequentes, dois Ministros da Saúde deixaram o cargo por divergência de opiniões com o Chefe do Executivo (MAZUI, 2020; ADORNO, 2020). Além disso, o país testemunhou uma série de episódios e crises que dividiram a sociedade e fizeram com que a pandemia, inicialmente um problema de saúde, também se tornasse um problema político. 
O cenário descrito mostrou-se bastante favorável à desinformação. De janeiro a junho de 2020, a Lupa - agência de notícias que se ocupa de verificar a fidedignidade das informações divulgadas na web - identificou 229 relatos falsos a respeito do novo coronavírus. Dentre os conteúdos inverídicos que circularam no período estão afirmações de caráter conspiratório sobre a origem do vírus; divulgação de terapias e medicamentos sem lastro científico, supostamente capazes de debelar a doença; denúncias sobre caixões enterrados sem corpos e sobre a capacidade ociosa de hospitais; distorção dos números sobre a Covid-19 e questionamentos sobre as vacinas em desenvolvimento (QUEIROZ, 2020).

Cumpre sublinhar que a desinformação abrange qualquer forma de informação imprecisa ou enganosa divulgada com o intuito de causar dano ou visando o lucro (EUROPEAN COMMISSION, 2018). O fenômeno não é novo e "envolve informação descontextualizada, fragmentada, manipulada, retirada de sua historicidade, tendenciosa, que apaga a realidade, distorce, subtrai, rotula ou confunde" (BRISOLA; BEZERRA, 2018, p. 3319). Além disso, segundo Zattar (2017), as informações cotidianas são mais suscetíveis à manipulação, uma vez que não contam com o mesmo rigor em sua confecção e disseminação que os conteúdos científicos.

O ambiente digital, cada vez mais incorporado à vida cotidiana dos indivíduos, permite amplo acesso à informação, muito embora também facilite a circulação da desinformação (EUROPEAN COMMISSION, 2018). Atrelado a isso, observa-se o fenômeno conhecido como pós-verdade. O termo ganhou destaque em 2016, quando foi eleito "palavra do ano" pelo Dicionário Oxford, e diz respeito à influência que resulta da emoção e das crenças pessoais na formação da opinião pública (ARAÚJO, 2020). Na argumentação de Schneider (2019, p. 74):

Sua especificidade consiste no papel das redes sociais digitais em sua formação, mediante a circulação de fake news, informações mentirosas de aparência jornalística que impregnam essas redes, em escala ao mesmo tempo massiva e ultra direcionada, com o intuito de favorecer determinados grupos de poder.

Segundo Santaella (2018), a pós-verdade, para além de estar vinculada à ampla disseminação de notícias falsas, também guarda vinculação com as bolhas informacionais ou câmaras de eco, que mantêm os sujeitos cativos às próprias crenças e fechados a ideias novas. A autora destaca a existência de uma segregação ideológica promovida por buscadores e mídias sociais, que apresentam ao usuário visões unilaterais acerca dos diversos conteúdos disponíveis.

Em sentido próximo, Wardle e Derakhshan (2017) observam que, no caso das mídias sociais, os conteúdos mais "bem-sucedidos" são aqueles que despertam emoções, principalmente os sentimentos de superioridade, medo ou raiva. Nesse cenário, identificar as práticas informacionais dos sujeitos nas mídias sociais auxilia a compreensão de como as informações falsas ou mal-intencionadas se espalham, além de aprofundar o entendimento do fenômeno da pós-verdade e do funcionamento das bolhas informacionais.

Os estudos de práticas informacionais sustentam que a necessidade de informação está relacionada ao contexto social e cultural do usuário e nem sempre é explícita. Assim, a interação do usuário com a informação se dá de forma recíproca, em que o sujeito atribui valor à informação por meio de significados culturais ao mesmo tempo em que também contribui para produzir e reforçar esses significados (BERTI; ARAÚJO, 2017). 
Tabosa, Tavares e Nunes (2016) esclarecem que a noção de práticas informacionais permite que se compreenda como os indivíduos atribuem significados às suas ações cotidianas relacionadas à informação. Em tal perspectiva, o usuário é visto como sujeito informacional e o que se valoriza é a relação dialógica entre o indivíduo e seu contexto, em que um constitui e influencia o outro (DUARTE; ARAÚJO; PAULA, 2017).

\title{
OBJETIVOS E METODOLOGIA
}

A pesquisa, em andamento, tem por objetivo investigar as práticas informacionais dos usuários em relação às notícias que circulam nas mídias sociais, no contexto da pandemia da Covid-19. Pretende-se, desse modo, averiguar quais temas despertam mais interesse nos internautas, como os diferentes grupos encaram os acontecimentos e de que modo as práticas podem, eventualmente, se alterar ao longo do tempo.

De natureza qualitativa, o estudo apresenta horizonte temporal longitudinal (SEKARAN, 2003), uma vez que os dados que o embasam têm sido coletados ao longo do tempo. Esta estratégia permite que se observe mudanças no comportamento dos internautas de acordo com a evolução da pandemia.

O método de pesquisa empregado é a Netnografia, técnica culturalmente orientada, que visa ao estudo das interações sociais mediadas pela tecnologia (KOZINETS, 2010). De acordo com Kozinets (2010), a netnografia é de uso frequente em pesquisas aplicadas à publicidade on-line, bem como em investigações que envolvam identidade, relações sociais e criatividade. Corrêa e Rozados (2016) sustentam que o método consiste numa adaptação da etnografia tradicional, que leva em conta as particularidades do ambiente digital.

\begin{abstract}
A netnografia difere de outra pesquisa qualitativa na internet porque ela oferece, sob a rubrica de um único termo, um conjunto rigoroso de diretrizes para a realização de etnografia mediada por computador e também, de maneira importante, sua integração com outras formas de pesquisa cultural (KOZINETS, 2010, p. 23).
\end{abstract}

Silva (2015) explica que, nesse método, três tipos de informações podem ser coletadas: dados arquivais, que consistem em conteúdos sobre o grupo pesquisado e que não envolvem diretamente o pesquisador; dados extraídos, estes adquiridos por meio da interação do pesquisador com os participantes, como entrevistas e bate-papos; e dados de notas de campo, em que o pesquisador relata suas experiências sobre as práticas dos membros da comunidade pesquisada e as interações entre eles, bem como sua própria participação. De acordo com Kozinets (2010), ao registrar suas próprias impressões e sentimentos acerca da comunidade estudada, o analista amplifica a sua sensibilidade em relação ao fenômeno.

No estudo, o pesquisador posiciona-se como observador, sem interagir diretamente com o grupo, a fim de não influenciar o comportamento dos seus membros. Com isso, optou-se por utilizar dados arquivais, uma vez que permitem a observação das práticas dos usuários da forma mais natural possível, sem qualquer interferência. Complementarmente, conta-se com os dados de notas de campo, em que são registradas, pelo investigador, suas percepções sobre os membros do grupo, bem como a interação entre eles.

Para atingir o objetivo proposto, três grupos públicos do Facebook (denominados A, B e C) têm sido monitorados constantemente, a fim de se averiguar os modos como os internautas lidam com os conteúdos sobre a crise de saúde que circulam na 
mencionada rede social. O Facebook foi escolhido por ser o quinto site de mais acessado no Brasil, sendo o primeiro dentre as redes sociais, segundo o Alexa Traffic Rank (ALEXA, 2020).

Dos grupos selecionados, um (A) foi criado especificamente para discussões acerca do novo coronavírus, outro (B) reúne apoiadores do Presidente brasileiro e o último (C) abarca indivíduos que se posicionam contra o Governo Federal. Os grupos B e C, de cunho político, foram inseridos na pesquisa pelo fato de as discussões a respeito da pandemia terem assumido, em muitas ocasiões, viés ideológico e partidário. Todos os grupos são classificados no Facebook como públicos, visíveis a qualquer pessoa e de interesse geral.

O grupo A foi criado em 25 de janeiro de 2020 e, no início da coleta de dados, era composto por 46.026 membros. O grupo B existe desde 29 de dezembro de 2019 e contava com 81.996 integrantes na época em que a coleta foi iniciada. O grupo $C$ foi fundado em 6 de agosto de 2019 e apresentava 22.495 partícipes no começo da coleta de dados.

Na pesquisa, levam-se em conta os assuntos mais comentados e mais compartilhados pelos internautas, a fim de se averiguar quais temas despertam maior interesse em cada um dos grupos; por meio da análise dos comentários, verifica-se como os indivíduos reagem aos acontecimentos. Além disso, examina-se quais as fontes das publicações analisadas, bem como alterações nas práticas dos usuários, no curso do tempo.

No que tange ao tratamento dos dados, emprega-se a análise de conteúdo que, conforme Bardin (1977), consiste numa descrição objetiva e sistemática dos temas contidos nas mensagens, capaz de ensejar a interpretação do objeto de estudo. Para tanto, empreendeu-se uma categorização do material pesquisado, a fim de se compreender e interpretar os resultados.

\section{ANÁLISE DE DADOS E RESULTADOS PRELIMINARES}

O estudo encontra-se na fase de coleta de dados. Todavia, para fins do presente artigo, apresenta-se análise e resultados preliminares obtidos a partir do exame das publicações de dois dias específicos do ano de 2020: 10 de abril e 7 de julho.

Com isso, procedeu-se à análise de conteúdo das postagens mais comentadas e mais compartilhadas em cada um dos grupos em acompanhamento. As publicações foram categorizadas por temas de maior relevância nos grupos estudados. Vale ressaltar que os grupos apresentam comportamentos distintos e, por isso, ao se realizar a categorização do material, levaram-se em conta as especificidades de cada comunidade, descritas a seguir.

No grupo $A$, as publicações versam quase que exclusivamente sobre o novo coronavírus e costumam gerar debates, na maioria das vezes, respeitosos e polidos, entre os participantes, que demonstram real preocupação com a pandemia da Covid19. Os assuntos publicados não se repetem com frequência e geram quantidade mediana de comentários ou compartilhamentos, se comparados aos outros grupos estudados.

O grupo B detém menor número de publicações, quando comparado aos demais. Não obstante, é a comunidade com maior quantidade de comentários e compartilhamentos que, algumas vezes, chegam a ultrapassar os milhares. Vale observar, contudo, que apesar do elevado quantitativo, a maioria dos comentários 
ostentados nos "posts" limitam-se a reproduzir alguma expressão de protesto contra oponentes do Governo Federal. Percebe-se ainda que, frequentemente, o mesmo membro repete dezenas de vezes a mesma expressão. Raros são os debates entre os seus integrantes.

O grupo $C$ veicula grande número de publicações diárias, com poucos comentários e compartilhamentos em cada uma delas, se comparado às demais comunidades em estudo. Observa-se, entretanto, grande repetição no teor das mensagens publicadas. Os comentários costumam ser breves e, normalmente, endereçam críticas ao Governo, mas não se limitam às frases de protesto observadas no grupo B. Poucos debates aparecem no grupo.

Para fins de categorização, consideraram-se as postagens com número igual ou superior a 100 comentários ou compartilhamentos. Quando uma publicação de idêntico conteúdo aparece mais de uma vez, ela é contabilizada como uma única postagem, somando-se, a seguir, os seus comentários e compartilhamentos. Nos grupos B e C, somente foram consideradas as publicações que guardam alguma relação com a pandemia.

A fonte das publicações também foi observada e divide-se em três categorias: membro, mídia tradicional e mídia engajada. A categoria membro diz respeito a postagens de autoria do próprio usuário ou de outros internautas, que o participante compartilha com sua comunidade. Aparecem, normalmente, na forma de frases chamativas ou imagens, satíricas ou não, sobre determinado assunto. Por mídia tradicional, entende-se as matérias publicadas em algum veículo de imprensa vinculado aos tradicionais grupos de mídia, como Globo, Folha de S. Paulo, Abril, BBC, dentre outros. A fonte mídia engajada é composta por sites que republicam matérias originárias das mídias tradicionais, adaptando-as de forma a favorecer alguma ideologia (TOLEDO, 2018).

O dia 10 de abril foi escolhido por ser a data inicial da coleta de dados. Na ocasião, o Brasil seguia no enfrentamento da pandemia há pouco mais de um mês, sendo que muitos Estados e Municípios haviam adotado medidas para promover o distanciamento social, como o fechamento das escolas e do comércio não essencial. $O$ Chefe do Executivo Federal, contudo, insistia na minimização do problema, tendo sido filmado, no dia anterior, passeando por Brasília sem máscara e cumprimentando pessoas. De acordo com Mello e Gaier (2020), decorreu de tal postura, amplamente divulgada pela mídia, o enfraquecimento das medidas de isolamento em diversas localidades.

Naquela data, foram analisadas 119 postagens do grupo $A$, todas referentes à pandemia da Covid-19, sendo que 15 publicações contavam com 100 ou mais comentários e 8 resultaram em 100 ou mais compartilhamentos. Das 70 publicações do grupo B, 42 faziam referência à pandemia, sendo que 16 receberam 100 ou mais comentários e 23 foram compartilhadas por pelo menos uma centena de vezes. No grupo C, das 115 publicações capturadas, 70 diziam respeito à crise de saúde, sendo três com 100 ou mais comentários e uma com 100 ou mais compartilhamentos. Ressalta-se, contudo, que neste último grupo, 21 publicações faziam referência ao passeio do Chefe do Executivo pela Capital Federal, somando 146 comentários e 171 compartilhamentos sobre o tema, razão pela qual foram também incluídas na classificação.

O quadro 1 apresenta as categorias temáticas que mais receberam comentários nos grupos analisados, bem como o número de publicações encontradas sobre cada tema, no dia 10 de abril de 2020. 
Quadro 1 - Categorias temáticas mais comentadas em 10/04/2020

\begin{tabular}{|c|c|c|}
\hline & Temas mais comentados & No de publicações \\
\hline \multirow{9}{*}{ Grupo A } & Números da Covid-19 & 03 \\
\hline & Vítimas da doença & 03 \\
\hline & Dúvidas sobre a transmissão & 02 \\
\hline & Dúvidas quanto ao futuro & 02 \\
\hline & Falta/ atraso nos testes & 01 \\
\hline & Isolamento & 01 \\
\hline & Avanço da pandemia no país & 01 \\
\hline & Descobertas científicas & 01 \\
\hline & Defesa dos jornalistas & 01 \\
\hline \multirow{9}{*}{ Grupo B } & Críticas ao Governador de SP & 05 \\
\hline & Auxílio emergencial & 02 \\
\hline & Cloroquina/ Hidroxicloroquina & 02 \\
\hline & Isolamento & 02 \\
\hline & Críticas ao STF & 01 \\
\hline & Passeio do Presidente da República (PR) & 01 \\
\hline & Negacionismo & 01 \\
\hline & Crítica à Rede Globo & 01 \\
\hline & Crítica ao Partido dos Trabalhadores (PT) & 01 \\
\hline \multirow{4}{*}{ Grupo C } & Passeio do PR & 11 \\
\hline & Curandeirismo & 01 \\
\hline & Negacionismo & 01 \\
\hline & Fechamento de igrejas & 01 \\
\hline
\end{tabular}

Fonte: desenvolvido pela autora

O quadro 2 exibe a relação dos temas que foram mais compartilhados nos grupos em análise e a quantidade de publicações em que cada assunto pôde ser observado, no dia 10 de abril de 2020.

Observa-se que, no grupo $A$, os assuntos que despertaram maior interesse da comunidade dizem respeito ao aumento do número de casos, aos relatos sobre vítimas da doença, às dúvidas quanto a transmissão do novo coronavírus e à insegurança em relação ao futuro. Além disso, esse grupo compartilhou, majoritariamente, matérias a respeito de descobertas científicas sobre a Covid-19. Em relação às fontes, 50\% das publicações analisadas tinham origem nos membros e a outra metade, na mídia tradicional.

Percebe-se que o foco do grupo é ampliar a informação dos membros a respeito da Covid-19. Assim, a maior parte das publicações mostra-se imparcial e os integrantes costumam dialogar educadamente. Em poucas situações, contudo, iniciaram-se discussões de cunho político nos comentários. Vale ressaltar, ainda, que nessa comunidade, alguns participantes sugerem ao grupo os mais diversos tratamentos para a doença, normalmente sem nenhum respaldo científico. Nesses casos, nota-se preocupação e vontade de ajudar por parte dos membros, muito embora tais práticas 
aprofundem o quadro de desinformação observado na atualidade e confirmem a explanação de Zattar (2017) de que as informações trocadas cotidianamente são mais vulneráveis à manipulação e à imprecisão de seu conteúdo.

Quadro 2 - Categorias temáticas mais compartilhadas em 10/04/2020

\begin{tabular}{|c|c|c|}
\hline & Temas mais compartilhados & No de publicações \\
\hline \multirow{7}{*}{ Grupo A } & Descobertas científicas & 02 \\
\hline & Números da Covid-19 & 01 \\
\hline & Vítimas da doença & 01 \\
\hline & Falta/ atraso de testes & 01 \\
\hline & Pandemia no mundo & 01 \\
\hline & Recuperação dos doentes & 01 \\
\hline & Preocupação com idosos & 01 \\
\hline \multirow{9}{*}{ Grupo B } & Críticas ao Governador de SP & 06 \\
\hline & Isolamento & 05 \\
\hline & Cloroquina/ Hidroxicloroquina & 03 \\
\hline & Auxílio emergencial & 03 \\
\hline & Negacionismo & 02 \\
\hline & Críticas ao STF & 01 \\
\hline & Passeio do Presidente da República (PR) & 01 \\
\hline & Crítica à Rede Globo & 01 \\
\hline & Crítica ao PT & 01 \\
\hline \multirow{2}{*}{ Grupo C } & Passeio do PR & 21 \\
\hline & Curandeirismo & 01 \\
\hline
\end{tabular}

Fonte: desenvolvido pela autora

O grupo B revelou-se o mais comprometido politicamente. Com isso, grande parte das publicações analisadas consistia em ataques ao Governador de São Paulo, João Dória, por conta das medidas restritivas impostas no Estado. A comunidade também elogiou o Governo Federal pela concessão de auxílio emergencial à parcela menos favorecida da população, além de defender o uso da hidroxicloroquina para tratar a Covid-19, salientando que, com essa medida, o problema de saúde seria resolvido. As medidas de isolamento adotadas por Estados e Municípios foram duramente criticadas. $\mathrm{Na}$ visão dos internautas, essas regras ferem os direitos individuais dos cidadãos e não caberia a sua imposição pelo Poder Público.

Quanto às fontes das mensagens, constatou-se que a maioria das publicações era proveniente de membros e apenas uma tinha origem na mídia engajada. Outro ponto que merece destaque é a linguagem adotada pelo grupo nos comentários a respeito do Governador de São Paulo, carregada de agressividade e, muitas vezes, entremeada de termos ofensivos.

O assunto dominante no grupo $\mathrm{C}$ foi o passeio do Chefe do Executivo pela Capital Federal, o que gerou revolta na comunidade, que considerou tal atitude um risco real para a saúde da população. Também foi muito comentado e compartilhado um vídeo em que um pastor ministrava cerimônia de "cura" a fiéis acometidos por Covid-19. Nos 
comentários da referida publicação, os internautas, na maioria das vezes, veicularam piadas com a crença dos seguidores do religioso. A maior parte das mensagens originava-se de membros do grupo, ainda que a mídia tradicional e a mídia engajada também constem como fontes.

Ressalta-se, ainda, que temas como o passeio do Presidente por Brasília e o negacionismo foram destaque nos grupos $B$ e C, muito embora a perspectiva sobre $o$ assunto tenha sido diferente em cada um. No caso da saída em ambiente aberto do Chefe do Executivo, enquanto o grupo $C$ revoltou-se com o ocorrido e afirmou que a iniciativa prejudicaria as medidas de isolamento, levando ao aumento de casos da Covid-19, o grupo B criticou a posição da imprensa em relação ao fato. Já a postura negacionista apareceu no grupo $B$ em mensagem que questionava a real existência da pandemia, enquanto os integrantes do grupo $C$ criticaram aqueles que não acreditam na crise de saúde. Com isso, percebe-se de que forma um mesmo assunto ou acontecimento pode ser visto sob prismas diferentes, sendo, muitas vezes, descontextualizados, a fim de privilegiar determinada posição ideológica, conforme apontado por Brisola e Bezerra (2018). Tais situações favorecem as bolhas informacionais, que reforçam visões unilaterais de determinado assunto. Para Santaella (2018), a resistência às novas ideias seria um dos mais graves prejuízos advindos de tais fenômenos.

Além de 10 de abril, o dia 7 de julho foi também selecionado, uma vez que, naquele marco temporal, pouco mais de quatro meses após o aparecimento do primeiro caso no país, diversos Estados e Municípios haviam iniciado o relaxamento das medidas de isolamento, mesmo ante o aumento registrado nos números da pandemia (VALENTE; SOUZA; TOKARNIA, 2020). Ademais, na manhã da referida data, o Chefe do Executivo anunciou o resultado de testagem positiva para o novo coronavírus (VERDÉLIO, 2020).

Foram capturadas 50 postagens do grupo A, todas referentes à Covid-19, sendo que três geraram 100 ou mais comentários. No caso das publicações mais compartilhadas, nenhuma tendo chegado a 100, o "post" mais disseminado resultou em 36 compartilhamentos. Das 23 publicações encontradas no grupo B, 16 faziam referência à pandemia, sendo 15 especificamente sobre a doença do Presidente, todas contando com 100 ou mais comentários e compartilhamentos. No grupo C, de um total de 300 publicações capturadas, 194 eram relativas ao novo coronavírus; destas, 178 faziam alusão à enfermidade do Chefe do Executivo. Cinco publicações receberam 100 ou mais comentários e duas apresentaram 100 ou mais compartilhamentos.

O quadro 3 apresenta os temas mais comentados nos grupos observados e o número de publicações encontradas sobre cada categoria temática, no dia 7 de julho de 2020. 
Quadro 3 - Categorias temáticas mais comentadas em 07/07/2020

\begin{tabular}{|l|l|l|}
\hline \multirow{4}{*}{ Grupo A } & \multicolumn{1}{|c|}{ Temas mais comentados } & No de publicações \\
\hline & Presidente da República (PR) testa positivo para a Covid-19 & 01 \\
\cline { 2 - 3 } & PR faz uso de hidroxicloroquina & 01 \\
\cline { 2 - 3 } & Transmissão do vírus pelo ar & 01 \\
\hline \multirow{3}{*}{ Grupo B } & PR faz uso de hidroxicloroquina & 06 \\
\cline { 2 - 3 } & Votos de melhoras ao PR & 04 \\
\hline \multirow{3}{*}{ Grupo C } & Pessoas que não desejam a melhora do PR & 03 \\
\cline { 2 - 3 } & PR testa positivo para a Covid-19 & 02 \\
\hline & Dúvidas quanto à doença do PR & 02 \\
\cline { 2 - 3 } & PR faz uso de hidroxicloroquina & 01 \\
\cline { 2 - 3 } & PR testa positivo para a Covid-19 & 01 \\
\cline { 2 - 3 } & PR retira máscara em entrevista & 01 \\
\hline
\end{tabular}

Fonte: desenvolvido pela autora

O quadro 4 expõe os temas mais compartilhados nas comunidades estudadas, bem como a quantidade de publicações observada para cada assunto, no dia 7 de julho de 2020.

Quadro 4 - Categorias temáticas mais compartilhadas em 07/07/2020

\begin{tabular}{|l|l|l|}
\hline & \multicolumn{1}{|c|}{ Temas mais compartilhados } & $\mathbf{N}^{\circ}$ de publicações \\
\hline Grupo A & Presidente da República (PR) testa positivo para Covid-19 & 1 \\
\hline \multirow{3}{*}{ Grupo B } & PR faz uso de hidroxicloroquina & 6 \\
\cline { 2 - 3 } & Votos de melhoras ao PR & 4 \\
\cline { 2 - 3 } & Pessoas que não desejam a melhora do PR & 3 \\
\hline \multirow{2}{*}{ Grupo C } & PR testa positivo para Covid-19 & 2 \\
\hline
\end{tabular}

Fonte: desenvolvido pela autora

Nota-se que, nesta data, nos três grupos estudados, a maioria dos debates relacionavase ao anúncio de que o Presidente havia testado positivo para a Covid-19. A discussão acerca do assunto, contudo, não foi a mesma. $O$ grupo $A$, normalmente neutro, dividiuse, com diversos integrantes duvidando da notícia ou ironizando o acontecido e outros desejando a recuperação do Chefe do Executivo. O grupo B fez votos de pronto restabelecimento ao mandatário e criticou duramente os depoimentos de algumas personalidades, que sustentaram haver justiça no adoecimento do Presidente. Já o grupo C, mostrou-se cético a respeito do anúncio, levantando dúvidas sobre a veracidade da enfermidade.

Além disso, outro vídeo divulgado no mesmo dia, em que o Chefe do Executivo afirmava estar se tratando com hidroxicloroquina também dividiu opiniões nos grupos B e C. Os integrantes do primeiro enalteceram a eficácia do medicamento, enquanto o segundo grupo acusou o Presidente de realizar propaganda do remédio. O grupo A 
apresentou opiniões divergentes, com alguns internautas defendendo o fármaco e outros criticando o seu uso para enfermos da Covid-19.

Percebe-se, nesses debates, forte presença do componente emocional nas posturas assumidas pelos usuários que, ou defendem qualquer atitude do Presidente, de modo indiscriminado, ou as criticam na sua totalidade, e com idêntico entusiasmo. Constatase, nesses embates, um afastamento da racionalidade e certo radicalismo de parte a parte, atitudes condizentes com o fenômeno da pós-verdade, em que a carga emocional contida nas mensagens importa mais que a veracidade ou incerteza do seu conteúdo, conforme observado por Araújo (2020).

Levando-se em conta as duas ocasiões abordadas, nota-se que, no grupo A, o conteúdo emocional marca presença, sobretudo na insegurança dos internautas em relação aos desdobramentos da crise de saúde e na descrença referente a algumas notícias, geradoras de indagações acerca de sua confiabilidade. Embora existam poucas publicações de conteúdo ideológico, discussões desse tipo se fazem notar nos comentários, levando a algumas observações exaltadas, principalmente quando as postagens dizem respeito a alguma atitude do Chefe do Executivo. Além disso, é possível constatar a ocorrência de desinformação, sobretudo nas duvidosas "receitas" para cura ou prevenção da doença, que geralmente aparecem nos comentários sem que, no entanto, apresentem qualquer respaldo científico.

No grupo $B$, praticamente todas as mensagens guardam cunho emocional, oscilando entre a concordância incondicional com as ideias defendidas pelo grupo e o ódio manifesto ao que vai contra as suas crenças. Assim, as posturas e ideias propagadas pelo Presidente são defendidas sem nenhuma contestação, enquanto qualquer indivíduo ou manifestação contrários ao Governo Federal são rechaçados com veemência. Os integrantes do grupo $C$ utilizam intensamente o humor, o deboche e a ironia para criticar os que não lhes agradam. Esforçam-se, além disso, para desacreditar as mensagens contrárias às ideias que compartilham.

O componente ideológico se faz presente sobretudo nas comunidades B e C. Opiniões contrárias não são bem aceitas, o que reforça a bolha ideológica em que os respectivos membros estão inseridos, criando um universo desfavorável ao debate e à pluralidade de ideias. Assim, conforme explanado por Santaella (2018), os sujeitos apenas vislumbram reflexos de si mesmos, o que causa segregação ideológica e leva à cristalização das crenças.

\section{CONSIDERAÇÕES FINAIS}

Desde o início da pandemia, percebe-se que o tema assumiu elevada proporção nas redes sociais, impactando consideravelmente as práticas informacionais dos sujeitos. Por meio da pesquisa, é possível constatar que o valor que cada indivíduo atribui a determinada informação guarda relação direta com seu posicionamento ideológico e sua visão de mundo. Percebe-se, assim, a reciprocidade que se faz presente na interação entre usuário e informação, uma vez que, ao mesmo tempo em que o sujeito atribui valor a determinado conteúdo conforme suas crenças, ele também contribui para o reforço de tais valores.

A enorme quantidade de informação - científica, socioeconômica, política, comportamental, etc. - que circula acerca do novo coronavírus é capaz de confundir a todos, inclusive os profissionais da saúde na linha de frente do combate à Covid-19. A própria comunidade científica mostra-se imersa em dúvidas, incertezas e hesitações, razão pela qual, não raramente, altera recomendações e atualiza conclusões, muitas 
vezes provisórias, a respeito da pandemia. De um lado, a OMS prega o distanciamento social e o uso de máscara como método de prevenção à Covid-19; de outro, Estados e Municípios alternam relaxamento e retomada das medidas de quarentena, indivíduos proeminentes saem às ruas desprovidos de máscara e outros promovem remédios com duvidosa capacidade de curar os acometidos. Observa-se, ainda, nesse confuso estado de coisas, conflito constante entre dados oficiais, nos níveis Federal, Estadual e Municipal.

O desencontro de informações em relação ao tema é considerável, seja por falta de conhecimento sobre a nova moléstia, seja por motivos ideológicos. Além disso, as incertezas quanto ao futuro, a angústia e a ansiedade decorrentes da crise de saúde ajudam a criar um cenário ideal para a disseminação de desinformação. Dentre as inúmeras publicações que circulam nos grupos estudados, verifica-se a descontextualização de conteúdos que, mesmo quando provenientes de fontes confiáveis, acabam levando a interpretações tendenciosas e unilaterais dos fatos, o que resulta na distorção da realidade e, muitas vezes, no favorecimento de determinada perspectiva em relação à pandemia.

Diante de tal cenário, a população revela-se desorientada, sem saber ao certo quais atitudes adotar e quais dados considerar corretos. Do mesmo modo, a profusão de informações conflitantes a respeito da pandemia da Covid-19 favorece o fenômeno da pós-verdade, levando os indivíduos a acreditarem naquilo que lhes soa mais conveniente e a tomarem decisões com base em crenças e emoções.

As ideias propagadas nas comunidades virtuais em estudo evidenciam disputas ideológicas e de poder, refletindo e reforçando uma polarização que se faz presente na sociedade brasileira como um todo. Com isso, percebe-se que os indivíduos norteiam suas ações mais por orientações ideológicas do que por decisões racionais.

Em que pese a aparente neutralidade do grupo A, a segmentação ideológica torna-se evidente nas vezes em que as discussões se relacionam a medidas políticas. Em contrapartida, a existência de poucos debates nos grupos $B$ e $C$ provavelmente decorre do alinhamento ideológico de seus integrantes, o que evidencia as bolhas informacionais em que estão inseridos.

Em relação aos discursos empregados pelos participantes, observa-se, principalmente no grupo $B$, uma narrativa simplista e dicotômica, levando a um reducionismo que limita consideravelmente a contraposição de ideias acerca de um problema de saúde que atinge a todos, a despeito de crenças e cosmovisões.

Convencer a população a mudar sua rotina, a manter isolamento na própria residência, sempre que possível, e a adotar hábitos pouco confortáveis, como o uso frequente de máscaras, é tarefa que demanda enorme esforço conjunto e coeso, cientificamente orientado, por parte dos órgãos públicos de todas as esferas de governo, além dos agentes privados, como a mídia. Não é isso, contudo, o que se tem observado no Brasil, de modo que as disputas informacionais relativas à pandemia indicam que as questões inerentes à pós-verdade e à desinformação tendem a se reproduzir em outros contextos e realidades, ao menos no curso da década que se inicia, com impactos muito relevantes e imponderáveis para a saúde pública e para a gestão da vida, individual e coletiva. 


\section{REFERÊNCIAS}

ADORNO, Luis. Ministro da Saúde Nelson Teich deixa governo Bolsonaro após menos de 1 mês. Uol, 15 maio 2020. Disponível em:

https://noticias.uol.com.br/politica/ultimas-noticias/2020/05/15/nelson-teich-pededemissao-do-governo-bolsonaro.htm. Acesso em: 14 jul. 2020.

ALEXA. Top Sites in Brazil. 2020. Disponível em:

https://www.alexa.com/topsites/countries/BR. Acesso em: 23 jul. 2020.

ARAÚJO, Carlos Alberto Ávila. O fenômeno da pós-verdade e suas implicações para a agenda de pesquisa em Ciência da Informação. Encontros Bibli, v. 25, p. 1-17, 2020. Disponível em: https://periodicos.ufsc.br/index.php/eb/article/view/15182924.2020.e72673/43144. Acesso em: 25 jun. 2020.

BARDIN, Laurence. Análise de conteúdo. Lisboa, Portugal: Edições 70 LDA, 1977.

BERTI, llemar Christina Lansoni Wey, ARAÚJO, Carlos Alberto Ávila. Estudos de usuários e práticas informacionais: do que estamos falando?. Informação \& Informação, Londrina, v. 22, n. 2, p. 389-401, maio/ago. 2017. Disponível em: http://www.uel.br/revistas/uel/index.php/informacao/article/view/31462. Acesso em: 4 jul. 2018.

BEZERRA, Arthur Coelho; CAPURRO, Rafael; SCHNEIDER, Marco. Regimes de verdade e poder: dos tempos modernos à era digital. Liinc em Revista, Rio de Janeiro, v. 13, n. 2, p. 371-380, nov. 2017. Disponível em: http://revista.ibict.br/liinc/article/view/4073. Acesso em: 19 ago. 2019.

BEZERRA, Arthur Coelho; SCHNEIDER, Marco; SALDANHA, Gustavo Silva. Ascensão e queda da utopia tecnoliberal: a dialética da liberdade sociotécnica. In: ENCONTRO NACIONAL DE PESQUISA EM CIÊNCIA DA INFORMAÇÃO, 14., 2013, Florianópolis. Anais eletrônicos... Florianópolis: ANCIB, 2013. p. 210-220. Disponível em: https://ridi.ibict.br/handle/123456789/487. Acesso em: 27 out. 2019.

BRASIL. Ministério da Saúde. Brasil confirma primeiro caso da doença. 26 fev. 2020. Disponível em: https://www.saude.gov.br/noticias/agencia-saude/46435-brasilconfirma-primeiro-caso-de-novo-coronavirus. Acesso em: 14 jul. 2020.

BRISOLA, Anna; BEZERRA, Arthur Coelho. Desinformação e circulação de "fake news": distinções, diagnóstico e reação. In: ENCONTRO NACIONAL DE PESQUISA EM CIÊNCIA DA INFORMAÇÃO, 19., 2018, Londrina. Anais eletrônicos... Disponível em: http://hdl.handle.net/20.500.11959/brapci/102819. Acesso em: 13 jul. 2020.

BRITO, Ricardo. Bolsonaro volta a se referir ao coronavírus como gripezinha, critica governadores e gera reação. Reuters, 24 mar. 2020. Disponível em: https://economia.uol.com.br/noticias/reuters/2020/03/24/bolsonaro-volta-a-se-referirao-coronavirus-como-gripezinha-e-criticar-governadores-por-restricoes.htm. Acesso em: 26 mar. 2020.

CORRÊA, Maurício de Vargas, ROZADOS, Helen Beatriz Frota. Comportamento Informacional em comunidades virtuais: um estudo netnográfico do grupo de 
interesses SEER/OJS in Brazil do Facebook. Biblionline, João Pessoa, v. 12, n. 3, p. 112125, jul./set. 2016. Disponível em:

https://periodicos.ufpb.br/ojs2/index.php/biblio/article/view/28172. Acesso em: 10 jun. 2020.

DUARTE, Adriana Bogliolo Sirihal; ARAÚJO, Carlos Alberto Ávila; PAULA, Cláudio Anastácio de. Práticas Informacionais: desafios teóricos e empíricos de pesquisa. Informação em Pauta, Fortaleza, v. 2, n. esp., p. 111-135, out. 2017. Disponível em: http://periodicos.ufc.br/informacaoempauta/article/view/20650/31063. Acesso em: 21 jun. 2018.

EUROPEAN COMMISSION. A multi-dimensional approach to disinformation: report of the independent High level Group on fake news and online disinformation.

Luxembourg, Belgium: Publications Office of the European Union, 2018. Disponível em: https://ec.europa.eu/digital-single-market/en/news/final-report-high-level-expertgroup-fake-news-and-online-disinformation. Acesso em: 13 jul. 2020.

KOZINETS, Robert V. Netnografia: realizando pesquisa etnográfica online. Porto Alegre: Penso, 2010.

LAVADO, Thiago. Com maior uso da internet durante a pandemia, número de reclamações aumenta; especialistas apontam problemas mais comuns. $\mathrm{G} 1,11$ jun. 2020. Disponível em:

https://g1.globo.com/economia/tecnologia/noticia/2020/06/11/com-maior-uso-dainternet-durante-pandemia-numero-de-reclamacoes-aumenta-especialistas-apontamproblemas-mais-comuns.ghtml. Acesso em: 12 jul. 2020.

MARQUES, José. Depois do Twitter, Facebook e Instagram também apagam post de Bolsonaro. Folha de S. Paulo, 30 mar. 2020. Disponível em:

https://www1.folha.uol.com.br/poder/2020/03/depois-do-twitter-facebook-tambemapaga-post-de-bolsonaro.shtml. Acesso em: 31 mar. 2020.

MAZUI, Guilherme. Mandetta anuncia em rede social que foi demitido por Bolsonaro do Ministério da Saúde. G1, 16 abr. 2020. Disponível em:

https://g1.globo.com/politica/noticia/2020/04/16/mandetta-anuncia-em-rede-socialque-foi-demitido-do-ministerio-da-saude.ghtml. Acesso em: 14 jul. 2020.

MELLO, Gabriela; GAIER, Rodrigo Viga. Criticadas por Bolsonaro, medidas de isolamento perdem força. Terra, 9 abr. 2020. Disponível em:

https://www.terra.com.br/noticias/coronavirus/criticadas-por-bolsonaro-medidas-deisolamento-perdem-

forca,c15d801dd52071cda07b94288e710eecak4kosym.html?fbclid=IwAR3u8LVzQO3K k7bAwm6E1pR45QE-nbIN-lj6phoK1ltHNSYrHMlggxljgZ4. Acesso em: 12 abr. 2020.

ORGANIZAÇÃO MUNDIAL DA SAÚDE - OMS. Timeline of WHO's response to COVID19. 2020a. Disponível em: https://www.who.int/news-room/detail/29-06-2020covidtimeline. Acesso em: 14 jul. 2020.

ORGANIZAÇÃO MUNDIAL DA SAÚDE - OMS. WHO Director-General's statement on IHR Emergency Committee on Novel Coronavirus (2019-nCoV). 2020b. Disponível em: https://www.who.int/dg/speeches/detail/who-director-general-s-statement-on-ihremergency-committee-on-novel-coronavirus-(2019-ncov). Acesso em: 14 jul. 2020. 
QUEIROZ, Gustavo. Brasil entra em sua sexta onda de desinformação sobre a Covid19. Folha de S. Paulo, 1 jul. 2020. Disponível em:

https://www1.folha.uol.com.br/equilibrioesaude/2020/07/brasil-entra-em-sua-sextaonda-de-desinformacao-sobre-a-covid-19.shtml. Acesso em: 18 jul. 2020.

ROCHA, Janicy Aparecida Pereira, DUARTE, Adriana Bogliolo Sirihal, PAULA, Claudio Paixão Anastácio de. Modelos de práticas informacionais. Em Questão, Porto Alegre, v. 23, n. 1, p. 36-61, jan./abr. 2017.

SANTAELLA, Lucia. A pós-verdade é verdadeira ou falsa?. Barueri, SP: Estação das Letras e Cores, 2018.

SAVOLAINEN, Reijo. Information behavior and information practice: reviewing the "umbrella concepts" of information-seeking studies. The Library Quarterly, Chicago, v. 77, n. 2, p. 109-132, Apr. 2007.

SCHNEIDER, Marco. Competência crítica em informação (em 7 níveis) como dispositivo de combate à pós-verdade. In: BEZERRA, Arthur Coelho; SCHNEIDER, Marco; PIMENTA, Ricardo M.; SALDANHA, Gustavo Silva. iKrítika: estudos críticos em informação. Rio de Janeiro, RJ: Garamond, 2019. p. 73-116.

SEKARAN, Uma. Research methods for business: a skill-building approach. 4. ed. Nova Iorque: John Wiley, 2003.

SILVA, Suelen de Aguiar. Desvelando a netnografia: um guia teórico e prático. Intercom, v. 38, n. 2, p. 339-342, jul./dez. 2015. Disponível em: https://www.scielo.br/scielo.php?script=sci_arttext\&pid=S1809-58442015000200339. Acesso em: 3 jun. 2020.

TABOSA, Hamilton Rodrigues; TAVARES, Derek Warwick da Silva; NUNES, Jefferson Veras. História e epistemologia da Ciência da Informação: abordagem social em foco. Revista Interamericana de Bibliotecología, Medellín, v. 39, n. 3, p. 289-300, set./dez. 2016. Disponível em: https://aprendeenlinea.udea.edu.co/revistas/index.php/RIB/article/view/22702/207827 o. Acesso em: 26 jun. 2018.

TOLEDO, Diego. Conheça donos de sites de guerra política acusados de espalhar 'fake news'. Uol, 26 maio 2018. Disponível em:

https://noticias.uol.com.br/politica/eleicoes/2018/noticias/2018/05/26/conheca-donosde-sites-de-guerra-politica-que-se-espalham-como-noticia.htm. Acesso em: 15 jul. 2020.

VALENTE, Jonas. Covid-19: veja como cada estado determina o distanciamento social. Agência Brasil, 01 abr. 2020. Disponível em:

https://agenciabrasil.ebc.com.br/saude/noticia/2020-04/covid-19-veja-como-cadaestado-determina-o-distanciamento-social. Acesso em: 14 jul. 2020.

VALENTE, Jonas; SOUZA, Lusmilla; TOKARNIA, Mariana. Saiba como cada estado está retomando as atividades econômicas no país. Agência Brasil, 22 jun. 2020. Disponível em https://agenciabrasil.ebc.com.br/saude/noticia/2020-06/saiba-como-estadosbrasileiros-estão-retomando-a-atividade-economica. Acesso em: 14 jul. 2020. 
VERDÉLIO, Andreia. Presidente Jair Bolsonaro testa positivo para covid-19. Agência Brasil, 7 jul. 2020. Disponível em

https://agenciabrasil.ebc.com.br/politica/noticia/2020-07/presidente-jair-bolsonarotesta-positivo-para-covid-19. Acesso em: 14 jul. 2020.

WARDLE, Claire; DERAKHSHAN, Hossein. Information disorder: toward an interdisciplinary framework for research and policymaking. Strasbourg: Conuncil of Europe, 2017. Disponível em: https://edoc.coe.int/en/media/7495-informationdisorder-toward-an-interdisciplinary-framework-for-research-and-policy-making.html. Acesso em: 2 mar. 2020.

ZATTAR, Marianna. Competência em informação e desinformação: critérios de avaliação do conteúdo das fontes de informação. Liinc em Revista, v. 13, n. 2, p. 28529, nov. 2017. Disponível em: http://revista.ibict.br/liinc/article/view/4075. Acesso em: 10 jul. 2020. 